\title{
Editorial
}

\section{Social work between empirical explorations, different contexts, voices and conceptual challenges}

by

Åse Vagli

Associate Professor, Dr. Philos

Department of Social Studies, University of Stavanger

Norway

E-mail: aase.vagli@uis.no

DOI: https://doi.org/10.31265/jcsw.v15.i1.351

\section{(a) (1) (2)}

This work is licensed under a Creative Commons Attribution-ShareAlike 4.0 International License. 
I am happy to be able to present this issue in spite of the hardships experienced by social work writers worldwide because of the pandemic that struck the world. My first period as an editor of the Journal Comparative Social Work has meant a lot of learning by doing for me. Thanks to the experienced web editor Per Johan Kolstrup, the editorial team and the hard-working reviewers who have made this issue possible. And great thanks to Maury Saslaff for checking, correcting and improving the language in both the articles and the editorial.

This issue is presenting the journal in a revised layout. We hope this makes the journal more accessible and easier to use. New features include a 'keywork cloud' that may be useful for an 'advanced search' on the journal's publications, 'the most read last week', also providing the number of views and links to the article, statistics on the numbers of abstract views, with the number of pdf downloads also shown for each article. A DOI link is added to the box, which includes the link and statistics of each article, while the most read articles by the same author(s) provide easy access to the most read and popular articles written by the same author. Thanks to Mina Farmanbar, head engineer at the Stavanger University Library for doing this work.

Since its start in 2006, the Journal of Comparative Social Work has had as its ambition to publish studies in- and about social work around the world. Conducting a search through the different published issues in these 14 years, I think we may say that this ambition has been followed up on, even if there is a long way to go to be able to create a better balance between studies from the Global South versus the Global North. The concept of comparison may be seen as be operationalized in many ways. Bateson (1979:67-71) points out that comparison is the basic way of creating knowledge. By making comparisons possible, it is possible to discover something new, Batson argues. Comparing stimulates the ability to ask questions, which is the foundation for creating knowledge. So, by making descriptions from social work in different countries, from different social work contexts, and with different methods, the JCSW is creating a foundation for new knowledge within the field of social work. As defined by the National Association of Social Workers, social work is about enhancing human well-being and helping to meet the basic human needs of all people, with particular attention given to the need and empowerment of people who are vulnerable, oppressed and living in poverty (NASW Code of Ethics). 
This code of ethics places social work in challenges on several levels. To be able to understand the needs of people and be able to help, one has to understand the situation people are in on several levels, and in its many complexities. Thus, to listen to how people experience their own situation is vital; an emphatic understanding must therefore be developed by listening to the person's own experiences. Nevertheless, there has to be an understanding that reaches beyond the individual person that includes perspectives on structural forces and restraints. Social work is placed between- and together with the individual and the individual's own understanding of the situation, but must also have a perspective on social forces and structural factors producing the basic frames for individuals. Without understanding these forces, empowerment may not be developed.

The articles in this issue are well situated in these discourses about- and in social work. The articles represent rich empirical descriptions, in which the voices of the oppressed are opened up and presented in rich description, as there are articles from different sites, by different methods, and with different theoretical and conceptual approaches. The various articles represent different voices, including social workers, social work students and researchers' 'meta' reflective voices.

I therefore welcome you to learn, reflect and move from one context to the other in exploring and reflecting on the many sites and levels of social work knowledge production in this issue.

\section{Here is a presentation of the five articles in the order of their place in this} issue.

In the first article, we travel to El Paso in the state of Texas in the US, and are introduced to the situation of being homeless: How I became homeless: Stories of homeless shelter residents in EI Paso, Texas USA

The team of authors consisting of Yok-Fong Paat, Jessica Morales, Dwain Pellebon, Ray Tullius, Aaron Escajeda and Ruben Alcantara represent different positions of experience in working with homelessness, from academic researchers, directors, therapists and student backgrounds. The articles have a life story perspective, and let the voices of the homeless be heard in rich direct citations of their homelessness. 
The article points out the complexities in the situation, and urges the message to use different approaches, including personal, cultural and structural levels. In this way, the article represents both the individual and structural perspective in social work. And in following up with concrete messages about measures, I also find this article important in emphasizing that homelessness must not be reduced to personal deficits, and understood in terms of cultural traditions among an ethnic group (in this case Hispanics). In this way, the article also illustrates that knowledge from a specific site may be very useful in raising general questions. To reduce social problems to particularities in what is understood as pure cultural is very important in most social work fields.

The second article is entitled: Social work bachelor students' knowledge awareness during field practice: Students' perspectives

The authors Evelyn Sandøy Ottesen, Ingunn Tollisen Ellingsen and Elisabeth Willumsen link themselves to a dominant discourse in social work about various forms of knowledge, the relations between practical and theoretical knowledge in social work and the implication of this debate for social work education. The authors explore these topics by means of bachelor social work students voicing and reflecting on their practice experiences after they have completed their field placement period. The empirical material is from Norway, though the discussion and discourse are international. The authors place the discussion within a general discourse about research mindedness, and also about conflicting knowledge discourses within social work, such as the persistent discussion about evidential research-based knowledge versus what is often termed practical knowledge. Here, the research tool of $Q$ methodology is used in a fruitful way to explore the students' opinions and argumentations for their standpoints and reflections. The $Q$ method approach is also stimulation for the students' knowledge awareness, as the $Q$ methodology confronts the informants with different argumentations, and thus may enhance awareness. One of the authors concluding sentences may well be cited here: 'The students are tomorrow's practitioners, and their voices and experiences are important and provide valuable insights.' 
The third article is entitled: Immigrant family socialization: Perspectives from adult children of Mexican origin and their parents in the United States Authors: Yok-Fong Paat, Monica Chavira, Rosemarie De La Hoya and Mitsue Yoshimoto

In this well written and interesting article, Yok Fong Paat and her writing team provide us with rich insights into important global issues, namely how families handle intergenerational communication and work to bridge differences due to immigration and acculturation processes. The authors emphasize the compromising strategies and mutual respect, acceptance, openness and realistic expectations in the communication between the generations. It is a positive optimistic perspective we are encountering in the article, in contrast to a dominant postulation of the acculturation gap-distress model. Here again, there are insights from a specific time and place, but the topic is relevant across place, and adds to the immigrant literature. It is also highly relevant for social work practitioners in giving perspectives on the successful adaptation and resilience factors of immigrant families. I recommend this article as a very interesting and good read!

The fourth article: Social workers understanding of extended families position in child welfare in Lithuania, Chile and Norway by the authors: Siv Oltedal, Ingunn Studsrød, Rasa Naujanienè and Carolina Muñoz Guzmán

Here, we are taken into a cross-cultural comparative analysis that explores how social workers understand 'family', and how they involve the extended family in child protection work. The author team is also cross-cultural, and illustrates how research exhibits cross-cultural interaction building and knowledge sharing. I think that including more than one nation in the comparison is interesting, insofar as comparing a nation from the Global North and the Global South may have pitfalls that have to be discussed.

In the last article in this issue: The establishment (and disestablishment) of social work in Britain: The ambivalence of public recognition, Jonathan Parker takes the reader into a meta-reflection on social work. He starts with a historic perspective on social work in Britain, and with conceptual help from psychoanalytical concepts he 
develops a thought provoking analysis. The examples are taken from an area within social work which is one of the most complex and controversial, namely child protection work. The main analytical point of departure is social work, as placed between the vulnerable human beings, the marginalized, the disadvantaged and the state establishment, and between the power and the powerless. This position places social work in an ambivalent symbolic field that has consequences for social workers' practice and the integrity of social work. This is a trope that I recognize, and have analysed in my own doctoral work (Vagli, 2009). Parker argues that the concept of sacrifice is linked to the schism of doing good by what is experienced as doing bad, and that the result demonstrates a strong ambivalence in social work practice. Parker writes: 'Social work is both a loved and hated feature of society. It is blamed for tragedies, yet sought out when there are social and intrapersonal needs.' Yes, I agree that the psychoanalytical concept of sacrifice gives meaning to the deeprooted ambivalence built into social work practice.

Parker also points to the dangers in producing a mythology of the social worker as savior due to charisma and personality. He emphasizes the shared praxis and collective identity based on what he terms 'active technologies of resistance', to stand alongside marginalized people, and not to remain a part of the system by assuaging the guilt of society.

This is a strong and challenging article from Parker, and thanks for sending it to the JCSW. 
Journal of Comparative Social Work 2020/1

\section{References}

Bateson, G. (1979). Mind and Nature: A Necessary Unity. London: Wildwood House.

Vagli, Å. (2009). Behind Closed Doors. Exploring the Institutional Logic of Child Protection Work. Dissertation for the degree of doctor philosophiae (Dr. Philos) University of Bergen. Norway. 